\title{
Event review: Central Narmada Basin Paleoanthropology Fieldschool
}

\author{
Parth R. Chauhan ${ }^{1}$, Prabhin Sukumaran ${ }^{2}$ \\ 1. Department of Humanities and Social Sciences, Indian Institute of Science Education and Research (IISER) \\ Mohali, India. Email: parthrc@iisermohali.ac.in \\ 2. Department of Civil Engineering, Charotar University of Science and Technology (CHARUSAT) Gujarat, \\ India. Email: prabhinsukumaran.cv@ charusat.ac.in
}

In comparison to other subjects in Indian archaeology and Quaternary studies, paleoanthropology has declined significantly in recent decades as a prominent academic discipline in the Indian Subcontinent. Most archaeological research and teaching in South Asia are largely focused on younger time periods, primarily the protohistoric or Chalcolithic and historical phases. In addition to lack of general interest and lack of popularization, another major reason for this decline in paleoanthropology may be the methodological challenges in interpreting complex paleoanthropological records, e.g., landform assemblage, paleoenvironmental reconstructions, assessing contextual integrity of the archaeological evidence (compared to younger sites) and so forth. Due to inadequate preserved evidence compared to younger archaeological sites, the study of human history during the Quaternary demands a multi-disciplinary approach with highly sophisticated and extensive field-based surveys and integrated scientific analyses from geological perspectives. In comparison to those periods where individual sites are extensively studied, Quaternary research involves geological and geochronological questions in relation to landform-based climatic interpretations and ecological reconstructions. Paleoanthropological research in the past has often focused on just reporting new Paleolithic or paleontological occurrences and artifact descriptions and basic assemblage compositions. What is now required from paleoanthropological sites are data and interpretations from within Quaternary studies such as paleoenvironmental reconstructions, geochronology, palynology, sedimentology, geomorphology and vertebrate paleontology, Unfortunately, very few academic departments and institutions are able to offer students and researchers a platform to learn and apply the practical and multidisciplinary methodological aspects of paleoanthropology such as surveying for lithic and fossil sites, excavating and documenting paleontological, Paleolithic and rock art sites, properly logging relevant stratigraphic sections and correlating regional stratigraphy, proper sediment sampling for relevant geochronological applications and so forth. Moreover, most students who learn about such topics through classroom lectures are rarely given opportunities to visit such sites first-hand to understand and appreciate their geological contexts, geographic and ecological settings and the manners in which such sites are identified. The lack of such multidisciplinary applications and knowledge centres may be

Published by the School of History, Classics and Archaeology, University of Edinburgh ISSN: 2055-0472. URL: http://journals.ed.ac.uk/lithicstudies/

This work is licensed under a Creative Commons Attribution 2.5 UK: Scotland License. 
also affecting the lack of interest to pursue paleoanthropological research during postgraduate and doctoral degrees.

With all of these issues in mind, IISER Mohali and CHARUSAT planned and conducted a multidisciplinary paleoanthropology fieldschool with a primary objective of planting an 'anthropology' seed in the minds of younger researchers for future avenues of research interests. The field lectures and methodological demonstrations were carried out in the Central Narmada Basin near Hoshangabad as the region preserves a rich diversity evidences of prehistoric archaeology, Quaternary geology and fossil sites. The one week program was held from $23^{\text {rd }}$ to $29^{\text {th }}$ December, 2015. The course was widely announced through Facebook, email and personal communications. Out of all interested applicants, 15 participants (out of which 13 attended) were selected by their areas of interest and study, geographic locality and statement of purpose. Participants included faculty, doctoral researchers and postgraduate students in diverse areas, such as geology, archaeology and history. All participants hailed from different states of India, e.g., Mizoram, Delhi, Maharashtra, Uttarakhand, Kashmir and Kerala, as well as from Bangladesh.

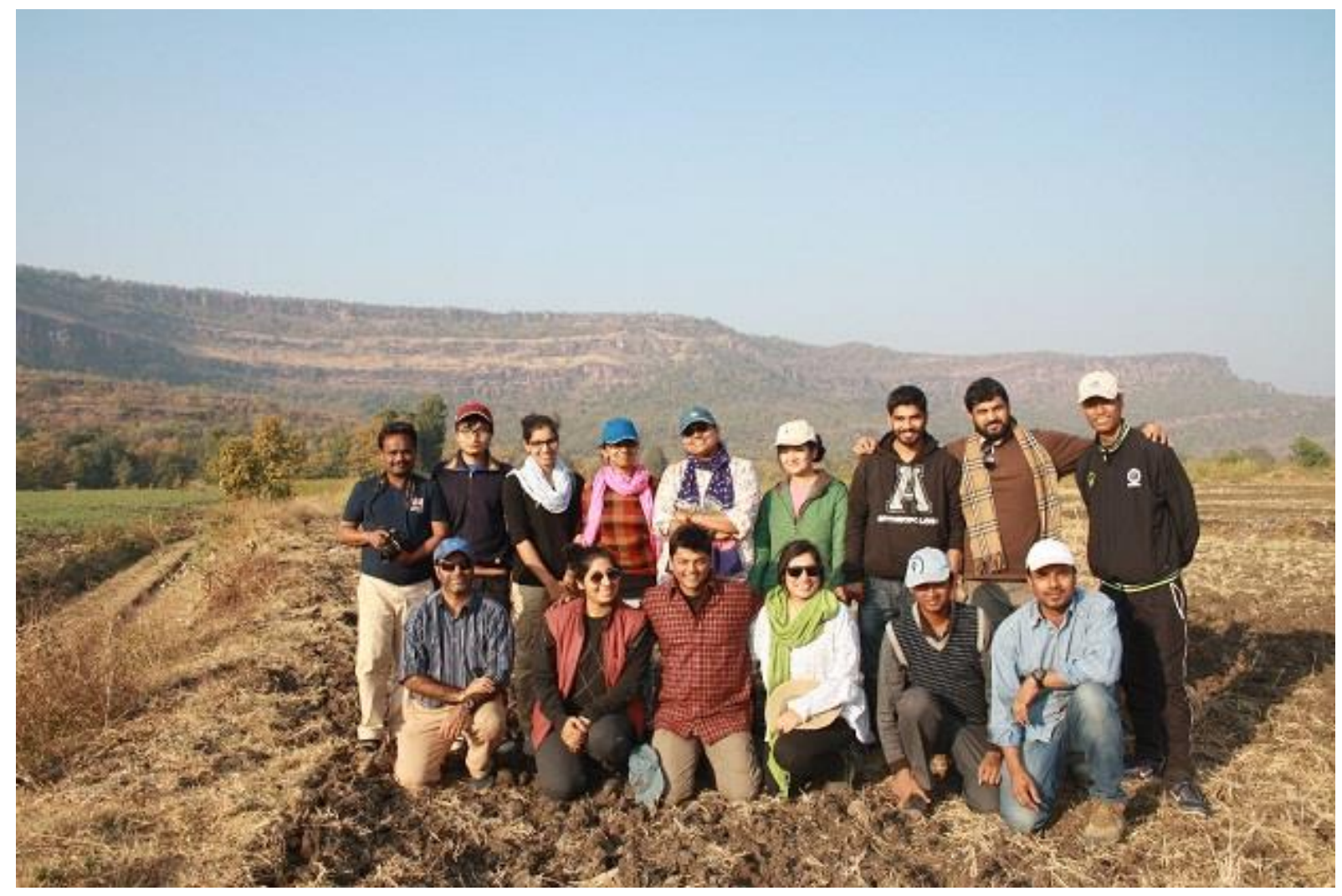

Figure 1. The participants and resource staff in the paleoanthopology fieldschool.

All participants were taken to key paleoanthropological sites and Quaternary typesections in the region, such as Hathnora, Surajkund, Dhansi and other comparable occurrences, to teach them about section documentation, geological contexts, stratigraphy, geomorphology, geological interpretations and sampling for luminescence dating. In addition, they were also taken to Indira Gandhi Rashtriya Manav Sangrahalaya (IGRMS) in Bhopal and the sites of Bhimbetka, Sanchi and Ginnaurgarh so that they could appreciate the full temporal, contextual and cultural breadths of the regional archaeological record. Parth R. Chauhan (Assistant Professor of Archaeology \& Paleoanthropology at IISER Mohali) and Shaik Saleem (Postdoctoral Researcher, IISER Mohali) provided lectures and information on Paleolithic archaeology and rock art respectively, and Prabhin Sukumaran (Assistant 
Professor, CHARUSAT Anand) provided lectures and information regarding basic methods and observations in Quaternary geology.

It is to be noted that the event was executed almost without any financial support from any agency or individual sponsor. The overall interest shown by the participants from different parts of the subcontinent, their active participation and discussions during the fieldschool and their positive feedback and satisfaction justifies the goal of holding such fieldschools on a regular basis, with methodological thrusts in Paleolithic archaeology, vertebrate paleontology and various Quaternary studies. Not only will such efforts motivate students to pursue new research avenues but also result in greater appreciation and knowledge of the various theoretical backgrounds in paleoanthropology, through first-hand observations of empirical data directly in the field.

\section{Acknowledgements}

PS is thankful to the Charotar University of Science and Technology for financial and administrative support for the participation in this fieldschool. PRC is thankful to IISER Mohali for continued institutional support. 